\title{
TENDENCIAS Y PERSPECTIVAS DE NUEVOS ESCENARIOS EDUCACIONALES
}

\author{
TENDÊNCIAS E PERSPECTIVAS DE NOVOS CENÁRIOS EDUCACIONAIS \\ TENDENCIES AND PROSPECTS OF NEW EDUCATIONAL SCENARIOS
}

\author{
Samuel Luis Velázquez Castellanos \\ Professor Doutor do Departamento de Educação I da Universidade Federal do Maranhão. \\ Pós-Doutorando da Universidade de Versailles - França. \\ samuel@ufma.br
}

RESUMEN: Se analizan en este trabajo las tendencias educacionales provocadas por las transformaciones en los planos económico, político, social y cultural. Se aborda la repercusión de estos cambios en la construcción de nuevos escenarios que respondan a las exigencias de la posmodernidad. Se reflexiona sobre el papel de la racionalidad instrumental deliberada en el mundo contemporáneo a partir de la perspectiva habermasiana. Se trata de las implicaciones de esta racionalidad en la configuración de la economía y del mercado del trabajo, en el desarrollo e implantación de las nuevas tecnologías informacionales y, en la formación/calificación del profesor, discutiéndose la proyección del trabajo docente, tanto en el marco de actuación individual y colectiva, como también en lo particular y en lo global que emerge en el campo de la educación.

PALABRAS CLAVE: Tendencias educacionales. Racionalidad instrumental. Escenarios educativos.

RESUMO: Analisam-se neste trabalho, as tendências educacionais provocadas pelas mudanças nos planos econômico, político, social e cultural. Aborda-se a repercussão destas transformações na construção de novos cenários educacionais que respondam às exigências da pós-modernidade. Reflete-se sobre o papel da racionalidade instrumental deliberada no mundo contemporâneo a partir da perspectiva habermasiana. Trata-se das implicações desta racionalidade na configuração da economia e no mercado do trabalho, no desenvolvimento e implantação das novas tecnologias informacionais e na formação/qualificação do professor, discutindo-se a projeção do trabalho docente, tanto no marco de atuação individual e coletivo, como também no particular e no global que emerge no campo da educação.

PALAVRAS-CHAVE: Tendências educacionais. Racionalidade instrumental. Cenários educativos.

ABSTRACT: Are analyzed in this work, educational tendencies provoked by changes in economic, political, social and cultural plans. Deals with the repercussion of these changes in the construction of new educational scenarios that meet the requirements of postmodernity. He reflects up about the role of rationality-instrumental deliberate in the contemporary world from Habermas' perspective. Say about the implications of this rationality in the configuration of economy and in the labor market, in the development and deployment of new information technologies and in training / qualification of the teacher, discussing the projection of teaching, in individual and collective activities of framework for action, but also in particular and global that emerges in the field of education.

KEYWORDS: Educational tendencies. Instrumental rationality. Educational settings.

Artigo recebido em janeiro de 2015

Aprovado em março de 2015

Cad. Pes., São Luís, v. 22, n. 1, jan./abr. 2015 


\section{1 | INTRODUCCIÓN}

En este trabajo abordo las tendencias educacionales que se presentan de forma célere e imprecisa, generadas por los constantes cambios en el plano económico, político, social y cultural, que de una forma o de otra, nos afectan directa o indirectamente, sea en lo colectivo, sea en lo individual, encontrándose estos segmentos intersectados, afectados y modificados en la polarización establecida entre lo global y lo particular, formando una encrucijada futurista que apunta caminos entrelazados con dimensiones y proposiciones alternativas, que sólo pueden ser entendidas, creadas y proyectadas, si intento analizarlas partiendo de nuestro espectro históricomemorialístico; en el cual, si "Marx tuvo sus [...] fantasmas [...] nosotros tenemos los nuestros, [...] memorias [que] no conocen más tales fronteras: [que] por definición, atraviesan paredes, [...] apariciones [que] día y noche engañan la conciencia y saltan generaciones" (DERRIDA, 1994, p. 49). Transformaciones múltiplas y simultáneas que al parecer una fuerza elemental y un trazo de nuestro tiempo, dificultan la compresión de la realidad y la planificación del futuro. Preverlo, a partir del análisis de los elementos decisionistas (que escogen un curso y no otro), depende de las imágenes ofrecidas por el passado/presente; deseos que no nacen de la nada, ya que incluso apuntando para el futuro están enraizados en nuestros espectros, constituidos estos por el "[...] por venir, él está siempre por venir, no se presenta sino como aquel que podría venir o revenir" (DERRIDA, 1994, p. 59).

Por otro lado, la movilidad física coexistiendo con la virtual desafía a los agentes educativos para repensar la escuela y su función frente a las nuevas conyunturas. Tomando como centro de análisis la sociedad y sus demandas, existe una serie de cuestiones que tratan de la nueva configuración de la economía y del mercado de trabajo, del desarrollo y de la implementación de las nuevas tecnologías informacionales, de la formación/calificación profesional en cuanto proceso continuo y de la postura del professor en ese contexto que precisan ser comprendidas, desmistificadas y resignificadas por preguntas pertinentes: ¿En qué afectan estos cambios a la educación? ¿Cómo repensar el trabajo docente en estas nuevas circunstancias? ¿Qué concepciones de formación pedagógica tendrían que ser revistas, discutidas y colocadas en práctica? ¿Qué nuevas estrategias políticas y compromisos éticos deben ser ventilados y ejercidos? ¿Qué escenarios educativos son posibles y deseables? En otras palabras, qué se puede hacer cuando estamos conscientes que cualquier progreso relativo "[...] al conocimiento de la necesidad es un progreso de la libertad posible [y que] nacemos determinados y tenemos un pequeño chance de libertarnos; nacemos en lo impensado y tenemos un chance bien reducido de tornarnos sujetos" (BOURDIEU; CHARTIER, 2011, p. 31).

En este mundo convulsionado, un aspecto esencial es transformar las dificultades en posibilidades, buscando diversos escenarios que respondan a la heterogeneidad de las problemáticas, donde las incertezas y los cambios deban ser llevados en consideración para la innovación, reconociendo la educación como un proyecto en curso (CASTELLANOS, 2013). Siendo así, es necesario no sólo distinguir la importancia del imaginario individual y colectivo, configurándolo y dándole forma de proyección futura, sino también es indispensable situarnos en el momento educativo actual, nutridos por el pasado, criticando el presente y construyendo caminos que aproximen posibilidades y estrategias que viabilizen nuevos saberes, otros espacios y formas innovadoras de intervención. Construcción o recontrucción que solamente será posible, si se intenta comprender los escenarios heredados, al entender que "la herencia no es jamás dada, es siempre una tarea. Permanece delante de nosotros, tan incontestable que, antes mismo de quererla o recusarla, somos herederos, y herederos enlutados, como todos los herederos" (DERRIDA, 1994, p.78). 


\section{2 | DESARROLLO}

Durante parte del siglo XX, principalmente después de 1945, el mundo estaba dividido entre dos modelos de producción, dependiente de las estructuras políticas e ideológicas que les daban sustento. En un extremo, el capitalismo como modelo occidental de organización de las relaciones económicas; del otro, el socialismo real, cuya expresión soviética atraía parte del Este europeo y de Ásia. En esa polaridad el intercambio de mercadurías aunque fuese intenso, sufría las limitaciones de la división geopolítica impuesta por la coexistencia de esas fuerzas globales que parecian dividir entre sí los territorios y las oportunidades de riqueza y desarrollo, a pesar que la mundialización y la globalización de las relaciones socioeconómicas no fuesen fenómenos esencialmente nuevos. En esa perspectiva, las alteraciones profundas están ocurriendo actualmente en los paradigmas contemporáneos relacionados con la producción de bienes/servicios y con el propio trabajo humano, el cual está aún contemplado en ese proceso de reproducción del capital.

La competición capitalista comprimida entre los terrenos probables se desarrolló, experimentando apogeos y crisis en clara obediencia a su naturaleza cíclica, creciendo a su alrededor los derechos humanos y sociales como fruto de las luchas por los derechos civiles establecidos y delimitados. El trabajo como mercaduría que es, fue atrayendo a su tiempo mayor valor, llegando a ostentar un excelente grado de retorno social a su propietário - el trabajador. Sin embargo, aunque la expansión del capitalismo haya encontrado sus límites y tenga establecido de cierta forma un pacto social con los actores envueltos en este proceso (cuadro muy claro en las naciones desarrolladas, incluso en países con estadíos intermedios como Brasil) - país emergente que expandió el capital por medio de políticas de substitución de importaciones, instalando industrias y fábricas extranjeras, que lo incluyó en el circuito de la mundialización industrial y comercial; aún así, la mayoría de los individuos como sujetos de la sociedad y constructores de su historia, continua distante de su propósito inherente, una vez que el déficit con la educación de calidad y con la formación obnilateral (a pesar de las políticas educacionales implantadas en los últimos diez años) se afirman en la división social del trabajo: los direcionados a pensar/conducir y los destinados a trabajar/cumplir órdenes.

Con el fin de la guerra fría y el derrumbamiento del muro de Berlín, el panorama mundial cambió, no existiendo más una potencia económica contrapuesta a la política del capital, el cual se legitimó con la fecha simbólica que representó la derrocada del socialismo soviético, en 1989. De esta forma, el mundo pasó a no imponer más fronteras a este sistema, lo que trajo consigo que "con el desaparecimiento del socialismo como inspiración política o como alternativa de lucha, las leyes del capitalismo se [transformasen] otra vez, en parte de la naturaleza" (McLAREN, 2000, p. 122), pasando a ser la esperanza del desarrollo de las naciones y de los gobiernos, los cuales permitieron la integración de sus países, ansiosos por las inversiones internas y extranjeras, donde el potencial económico es el grande elemento diferenciador en la sociedad de la información, iniciada en la década del 70 debido a una revolución tecnológica sin precedente.

En la sociedad industrial había un predominio del sector secundario (industria) y un crecimiento del terciario (servicios) en detrimento del sector primario (agricultura, pesca, minería, etc). Más tarde se desarrolló un nuevo sector (el cuaternario o informacional), en el cual, la información fue la materia prima y su procesamiento la base del sistema económico, existiendo diferentes modos de articulaciones que se resumieron en dos tendencias: el cambio en el proceso de producción y el surgimiento de nuevas actividades y profesiones. En esta dirección, las grandes corporaciones pasaron a representar la tendencia de la descolocación productiva, transfiriendo sus fábricas para locales donde había menor tradición sindical, salarios más bajos, además de la baja protección social; cuando no, tercerizaron la producción por medio de una red de pequeñas empresas loca- 
lizadas por varios países, multiplicadas y conectadas, encontrándonos actualmente incluidos o no, en una economía informacional, global y mundial, característica del industrialismo provocado por la revolución tecnológica de los últimos 35(treinta y cinco) años. Globalización del trabajo y del capital que causó transformaciones materiales en las prácticas culturales y en la proliferación de nuevas contradicciones entre capitalismo y trabajo, mostrando esa nueva etapa del desarrollo una hegemonía del capital especulativo financiero sobre el clásico capital de inversión industrial; o sea, "el fenómeno actual de la mundialización [...] es [...] la canibalización de lo social y de lo político y [es] como 'el fin de la explosión de la modernidad occidental"' (McLAREN, 2000, p.122).

El Estado Neoliberal corresponde a los pactos regionales y de liberación que surgieron en el escenario económico al final del siglo XX, pareciendo un proceso inevitable, causado por el desarrollo tecnológico. La forma de inserción de las economías nacionales en la globalización, parece insuperable por las fuerzas del mercado, en las cuales, las estructuras del mundo vital parecen estar amenazadas por la lógica de la diferenciación y la racionalización sistemática; es decir, por la nueva colonización del mundo. Reestructuración productiva que al tener una lógica y una dinámica propia en su formato, expresa la hegemonía del capital financeiro, avanza con la ideología del neoliberalismo, se define como una venganza del capital contra el trabajo y declara el triunfo de la racionalidad instrumental-deliberada; Legado dejado por los filósofos de la llustración, que "[...] quisieron utilizar esta acumulación de cultura especializada para enriquecer la vida cotidiana, [y] para organizar racionalmente la vida social [...]" (JAY, 2008, p. 208).

En este sentido, el capitalismo neoliberal es más que la opresión de clases denunciada por los marxistas y neomarxistas. En realidad, constitúyese en nuevas formas de explotación/dominación, nuevas formas de dependencia personal/esclavismo, condicionando nuestra vida social a los requisitos abstractos del mercado'. Se para Rigal (2000), tanto la modernidad como la postmodernidad en América Latina, fueron en su esencia nociones externas de otros escenarios importados que expresan "[...] la situación de dependencia y dominación en que estuvieron las sociedades latinoamericanas desde: [...] la primera fase de la globalización del capital que llevó su incorporación forzada al mercado mundial en el siglo XVI" (RIGAL, 2000, p. 175); para McLaren (2001, p. 123), el canto de la globalización, alternativamente celebrado y fatalista, "[...] se transformó en una cortina de humo capitalista que desarma cualquier resistencia al capital e impide que veamos la naturaleza real, y no demasiado nueva, del ataque [...] de los capitalistas [...] a los trabajadores [...]". Sistema económico difícil de ser entendido por no poderse separar del contexto, en el cual, las clases sociales existen pero están ocultas, escondidas en otros lenguajes de diferencias societales. Concepto substituido por otro menos antagónico (el status económico) donde las clases sociales son traducidas en diferencias de razas, de etnias o de géneros. Espacio neoliberal desenfrenado y degradado por el control del mercado, donde la mayoría eternamente excluida y condenada cada vez más a los infortunios de la pobreza, se le niega lo que le es propio a la naturaleza humana: la facultad de crear, imaginar, inventar y soñar. Realidad aparente que elude, ofusca e induce al final del túnel, al fin de la historia, al fin del individuo, en un proceso determinado, pesimista e irreversible, heredado por el Legado de la llustración.

¿Pero al final, puede haber luz en el fin del túnel....? Más que respuestas rápidas y recetas esquematizadas, preguntas constantes se hacen necesárias por los cambios inherentes al capitalismo en reinvención; a exemplo da política económica actual de austeridad en algunos países. ¿Por qué la lógica mercantil en este escenario es capaz de guiarnos en su convulsión transformista y

\footnotetext{
${ }^{1}$ Técnicas e instrumentalización de los procesos de racionalización-deliberada en función de la economía y del acúmulo de capital, a plusvalía; la esencia existencial del capitalismo y de sus diversas formas de explotación.
} 
ha ocupado el lugar del sujeto, arrastrándolo y obligándolo a acompañarla, como si el mercado fuese un ser pensante, cohabitando con el individuo (con conciencia aparentemente innata) que nos guía, que decide por nosotros y del cual, si no conseguimos seguirlo, seremos eternamente condenados y excluidos en nuestra propia condición de humanos? ¿Por qué en vez de percibir el fin de la historia, no conseguimos vernos como sujetos con posibilidades de construirla o direccionarla para otros sentidos y fines - no pensando en el Yo-individual, y sí para fines plurales, por medio de la acción comunicativa, que mediatizada por el argumento de validez, nos permita reconocernos en los Otros? En otras palabras, deberíamos entender que las luchas relativamente a las clasificaciones son "[...] tan reales cuanto las luchas de clases (si es que ellas podrían ser separadas) y que las representaciones abordadas del mundo social, además de producirlo, acaban por ser su expresión" (CHARTIER, 2011, p. 8); o sea, poderíamos enfrentarnos "[...] honestamente a los desafíos, críticas, al desenmascaramiento de las ilusiones, trabajar utilizando estas y construir todavía de un modo responsable una perspectiva comprensiva de la modernidad y sus patologías" (HABERMAS, 2008, p. 51).

Siendo así, en lo que Richard Rorty (2008, p. 242) trata de libertarse de la camisa de fuerza de la filosofía analítica queriendo destruir la filosofía de la conciencia, coincidiendo con Wittegenstein, al considerar que "[...] la filosofía misma es la enfermedad cuyos síntomas intentó curar previamente sin éxito", para demostrar la inutilidad de toda discusión sobre los fundamentos y límites del conocimiento humano; Habermas (2008) afirma que Rorty (2008) comete una falacia objetivista al creer que pueda sustituir de un modo conciente la concepción implícitamente normativa de los argumentos válidos mediante el concepto descriptivo de los argumentos que mantenemos como verdaderos en nuestra época. Según él, las convicciones sobre lo que se admite como verdad se fundamentan en el interés filosófico de considerar las prácticas sociales de justificación como "algo a más", que tales prácticas. Verdades basadas en el mejor argumento y desde una posición neoconservadora ${ }^{2}$, para que no se desmistifiquen las relaciones e intereses establecidos en tales prácticas. Proceso reflexivo que sólo será posible, por el entendimento filosófico (que conjuntamente con la ciéncia) nos auxilie a entender la influencia de los procesos económicos, políticos, sociales, culturales en la historia, y nuestro duplo papel: actores transformadores/transformados de/por la historia.

Por outro lado, considerando el crecimento de la Zweckrationalität, se para Marx Weber, en vez de conducirnos a la libertad universal, nos llevaría a la creación de la "jaula de hierro" de la racionalidad burocrática, de la cual no tendríamos como escapar, coincidiendo con McCarthy (2008) sobre el dominio de las fuerzas económicas y de las organizaciones burocráticamente organizadas en detrimento del supuesto Reino de la libertad; Horkheimer y Adorno, representantes de la Dialéctica de la llustración en sus últimos escritos, mantienen la idea del inevitable triunfo histórico de la racionalidad-instrumental, argumentando que su semilla está en los orígenes de la racionalidad occidental, denominada por ellos como la lógica de la identidad. Sin alternativa, "la Teoría Crítica se resignó; como mucho, pudo desenmascarar la sinrazón que existía en el corazón de lo que se consideraba como razón [...]" (McCARTHY, 2008, p. 277).

Habermas (2008), sin embargo, propone un análisis de las conexiones existentes entre conocimiento/interés, estimulando la rearticulación de la Teoría del Conocimiento (cuyo lugar ha sido usurpado por la Teoría de la Ciencia - por medio de la reflexión); contrariando totalmente al positivismo en la busca de "[...] una teoría de la modernidad, una teoría de la patología de la moderni-

\footnotetext{
${ }^{2}$ Aquellos que reniegan o pretenden frenar el proceso continuo de reflexión tratando de mantener el statu quo.

${ }^{3}$ Racionalidad instrumental deliberada.
} 
dad, desde el punto de vista de la realización - la deformada realización - de la razón en la historia" (HABERMAS, 2008, p. 17). Para este autor, no se requería nada más que repensar la cuestión de la racionalidad y de los procesos de racionalización, distinguiendo tres intereses cognitivos casi trascendentales e irreductibles: el técnico, el práctico y el emancipatorio social, arraigados a tres dimensiones de la existencia humana: el trabajo, la interacción simbólica y el poder. Además de concordar con la división kantiana de la cultura superior en ciencia, moralidad y arte, defiende la posición de Hegel al aceptarla como la interpretación standard (massgeblich) de la modernidad; aunque la crítica hegeliana apunte el no reconocimiento por Kant de las disyunciones existentes en las divisiones formales de la cultura, ignorando así la necesidad de unificación surgida de las separaciones producidas por el principio de la subjetividad.

Si para Habermas (2002b), era importante la formación de una voluntad no coaccionada en una comunidad de comunicación que tuviese lugar bajo las coacciones de cooperación como modelo de reconciliación de una sociedad civil bifurcada; para Rorty (2008) se había llevado muy en serio el problema kantiano, que condenó filósofos modernos a participar de los movimientos reduccionistas que intentaban justificar todo en el nivel científico, político o estético, como también a los no reduccionistas que mostraban lo contrario; negándose así la esencialidad de la filosofía moderna: la no permisión para que esas esferas coexistiesen de una manera no competitiva o, la prevalencia de una en detrimento de las otras. Segundo Hegel, esta razón emancipatoria dinámica sólo se daría por el Arte (Vermunf) ${ }^{4}$, el cual aparecería como figura prefigurativa de la redención y último testimonio de un mundo racionalizado.

Rorty (2008) afirma sobre Descartes (el fundador de la filosofía moderna) que este conservó los temas del pensamiento antiguo que Bacon intentó eliminar, manteniendo la idea platónica de que nuestra facultad humana más característica es la habilidad para manipular las "ideas claras y distintas", en vez de hacer hazañas de ingienería social. Para él, esta fue la contribución más importante y desafortunada de Descartes a la filosofia de la modernidad, ya que si hubiésemos llevado más en serio a Bacon (el profeta de la autoafirmación, contrario a la autofundamentación) no estaríamos enclausurados en la subjetividad de los filósofos modernos. Dessa forma, asumiríamos menos que la epistemología (la reflexión sobre la natureza y el status de la ciencia) eran las variables independientes del pensamento filosófico, en detrimento de la filosofía moral y la social consideradas como variables dependientes, y entonaríamos con dificultad el principio del moderno, ya que autoafirma las esperanzas en el futuro de la raza, en los éxitos imprevisibles de nuestros descendientes e impide "[...] pensar que la época moderna [no es más que] los sucesivos intentos para deshacerse del tipo de estrutura ahistórica que Kant ejemplifica diviendo la cultura en tres esferas de valores" (RORTY, 2008, p. 269).

El pensamiento nietzschiano, por su parte, aunque sus posicionamientos fuesen rechazados por Habermas (1990), por representar la destrucción de la filosofía de la subjetvidad (en su eterno sueño dionisiaco), coincide con Rorty (2008), al criticar en Além do Bem e do Mal, el cógito de Descartes. "Él dice 'yo pienso' y aqui el Sujeto determina el verbo: hay un Yo que piensa. Los modernos conciben lo inverso: 'pienso' determinante, 'Yo' determinado. 'Yo' sería entonces una síntesis realizada por mi pensamiento" (NIETZSCHE apud TOURINE, 2013, p. 118) y, la conciencia para la ciencia, es lo que hay de menos realizado y de más frágil en la evolución de la vida orgánica, de suerte que, cuando más un ser humano tiene conciencia, más multiplica los falsos pasos y actos fallos que lo hacen perecer.

Sin embargo, a pesar de que Habermas (2002a) considere válido el legado kantiano de la filo-

${ }^{4}$ Razón que se atualiza dinámicamente por medio de la historia. 
sofía trascendental denominándolo e identificándolo en las llamadas ciencias recontructivistas ${ }^{5}$, rompe con la idea de que tales investigaciones sean a priori. Él se fundamenta en los diferenciales que están implícitos, que las condicionan y las significan, reconociendo la investigación científica como hipotética, falible y empírica, al sustentar que una crítica emancipatoria no se puede apoyar en normas arbitrarias y sí en las mismas estructuras de las competencias comunicativas intersubjetivas. Habermas (2002b) a partir de su Teoría de la Acción Comunicativa propone el diálogo entre la filosofía y las ciencias recontructivistas para compartir las cuestiones de la racionalidad y el concepto de conciencia falible. La autocomprensión revisionaria del nuevo papel filosófico rompe con las aspiraciones de la filosofía primera en cualquiera de sus formas, inclusive con la Teoría del Conocimiento, no significando el abandono de la filosofía como guardián de la racionalidad, sino garantizando su inclusión en la historia. Esta autoreflexión de las ciencias consistiría en demostrar como se vincula y/o contrastan las prácticas de los científicos, con las prácticas de otros grupos, adoptando una función crítica; la determinada negación ad hoc. Nuevo enfoque que posibilitaría esclarecer el concepto de racionalidad comunicativa al escapar de las trampas del logocéntrismo occidental e intenta conseguir sus propósitos por medio del análisis potencial operativo de la racionalidad, la cual encuéntrase contenida en la práctica cotidiana de la comunicación.

Para él, es imposible defender el proyecto de la modernidad sacrificando la tradición que va desde Feuerbach, pasando por Marx y Freud, hasta la primera generación de la escuela de Frankfurt. No se puede entender el carácter del "mundo vital" a menos que comprendamos los sistemas sociales que lo configuran y no podríamos comprender los sistemas sociales, a menos que observemos cómo surgen a partir de las actividades de los agentes sociales. De ese modo, la síntesis del sistema y de las orientaciones del mundo vital se integran con la delineación de las diferentes formas de racionalidad y racionalización, siendo la racionalidad de los sistemas un tipo de racionalidad (deliberado-racional) y la racionalidad del mundo vital la (racionalidad comunicativa). En este sentido, la pretensión sociológica más importante de Habermas (2008) fue su tesis sobre "La seletividad", suponiéndola como la existencia de alternativas posibles que permitirían diagnosticar las patologías de la modernidad, transformando la hermenéutica de la sospecha, en la medida en que, "nos hemos transformado en los maestros de la sospecha de la hermenéutica de la sospecha" (HABERMANS, 2008, p. 51); lo que trajo consigo, que la Teoría de la Acción Comunicativa se constituyese en una nueva síntesis reconocida como el desarrollo principal de la teoría sociológica de nuestra época.

Si por un lado, Marx Weber intenta explicar el proceso de modernización como una "racionalidad progresiva", entendiendo por racionalización, el conjunto de tendencias interrelacionadas que operan en niveles diferentes o en varios subsistemas, indicando una formalización, una instrumentalización y una burocratización en aumento de acuerdo con una lógica o necesidad sistemática interna, y por otro, para los representantes de la tradición de la llustración, la historia aparecía como un progreso hasta la Razón, sin desconsiderar que para la tradición europea, ser racional ha significado una condición básica y una tarea de los seres humanos como seres humanos; Habermas (2008), en dirección contraria a la concepción de Weber, ha traducido el proyecto de una teoría crítica de la sociedad desde el marco conceptual de una filosofía de la conciencia (adaptada a un modelo de Sujeto-Objeto de cognición y acción) al marco conceptual de una historia del lenguaje y de la acción comunicativa.

\footnotetext{
${ }^{5}$ Dentro de las cuales se encuentran la Teoría Gramática Generativa de Chomsky, la Teoría del Desarrollo Cognitivo de Piaget, la Teoría del Desarrollo Moral de Kohlberg, entre otras, distinguiéndose de las ciencias analíticas-empíricas, las cuales son tipificadas por las ciencias naturales contemporâneas.
} 
Racionalidad comunicativa que está implícitamente en la estructura del habla humano, representando el standard básico de la racionalidad que comparten los hablantes competentes en las sociedades modernas. Racionalidad comunicativa que también se traduce en "[...] una actitud racional específica que los individuos adoptan hacia los otros y hacia si mismos, así como una relación específica de reconocimiento mutuo entre diferentes individuos (HABERMAS, 2008, p. 91). O sea, la intuición fundamental que hace trascender este autor de la Teoría Crítica de la primera generación de la escuela de Frankfurt fue, precisamente, entender que el dominio de la naturaleza exterior y el dominio de la naturaleza interior, siguen lógicas diferentes. En el primero, se procede aplicando leyes nomológicas a un objeto heterogéneo; en el segundo, hay un lugar donde se interiorizan las normas intersubjetivas, delimitando los tipos estructurales existentes en la naturaleza, en la sociedad y en el individuo: las estructuras de la racionalidad cognitivo-instrumental, las estructuras de lo práctico-moral y las estructuras de lo expresivo-estético.

Para Habermas (2002b), el conocimiento se torna una excentricidad y una extravagancia de naturaleza lingüística, ya que nada, ni nadie, tiene acceso al saber verdadero, sino por la intensa justificativa de pretensión de validez; es decir, quien crea tener el conocimiento a su disposición asume la posibilidad de una justificación discursiva de las pretensiones de verdades correspondientes, "[...] haciendo parte de la gramática de la expresión 'saber', que todo aquello que sabemos [pueda] ser criticado y justificado" (HABERMAS, 2002b, p.188). Por tanto, si el lenguaje es un trazo distintivo de la humanidad, la comunicabilidad también lo es, visto que está en el lenguaje la inclinación de la humanidad para la comunicabilidade, justificándose en esos términos su optimismo por las formas democráticas de convivencia social, lo que explica su defensa por una racionalidad comunicativa. Al igual que Kant, piensa que la ciencia moderna posee una dinámica teórica que se identifica en parte con la "Naturaleza de la Racionalidad", pero es imperativo aislarla y distinguirla de otras dinámicas, como la "Razón Práctica" y el "Interés Emancipatorio", para mantener válidos los resultados de la ciencia sin desencantar el mundo. En esa perspectiva, entiende que debe eliminarse la dominación del subsistema de la racionalidad cognitivo-instrumental sobre la racionalidad práctico-moral y la expresivo-estética, exaltando la posibilidad de que otros (jalgún día!) puedan dar continuidad a la historia humana y a la historia natural, con tanto cuidado que sean lo bastante sensibles para ser plausibles, y sin embargo, lo bastante fuertes para que permitan reconocer el lugar que ocupa el hombre en el cosmo (sheler), al menos en líneas generales.

Estos aspectos me autorizan a afirmar que el pensamento habermasiano se muestra fecundo con relación a la educación, cuando coloco diferentes cuestiones en esta dimensión: el tipo de racionalidad que orienta la acción pedagógica, la dinámica que predomina en el interior de la comunidad escolar y las relaciones de esta con la sociedad, las funciones de la educación y de las instituciones escolares, los espacios ocupados por el sistema de enseñanza y por el "mundo de la vida" en el cotidiano de la escuela; nociones que proporcionan importantes incógnitas sobre la concepción de la modernidad, racionalidad, lenguaje y comunicación, tornando posible una reflexión sobre el papel de la educación y de los professores. Por otro lado, la acción educativa (en cuanto acto intencional) precisa asentarse sobre parámetros y presupuestos capaces de conferir sentido y dirección a las propuestas desarrolladas, las cuales deben orientarse por finalidades que tienen como punto de partida una determinada concepción de mundo, de sociedad, de hombre, de conocimiento y de educación, lo que implica decisiones de carácter político expresas en intenciones formuladas mediante un processo de negociación, selección y consenso que posibilite caracterizar la escuela como el espacio de la acción comunicativa, de la interación, de la socialización y de la emancipación. El hecho de ser desconsiderada esta dimensión y caminar en dirección inversa, podría traer como consecuencia, la sobreposición de la dimensión técnica a la pedagógica, confiriéndole a la racionalidad-instrumental un espacio mayor que el necesario. 
De esa forma, antes de identificar la contribución del pensamiento habermasiano a la filosofía de la educación expongo las relaciones estabelecidas entre filosofía y educación, y por consiguiente, caracterizo el papel de la filosofía de la educación en cuanto actitud crítica y reflexiva sobre una práctica humana transformadora. En ese sentido, cabe perguntar qué significa pensar filosóficamente la educación, esbozando una aproximación entre la atitud filosófica y la práctica educativa; convencido que el acto educativo siempre intencional, mas ni por eso sustentado en una concepción nítida de educação (independentemente de su naturaleza) marca el proceso de inserción del hombre en la vida social e cultural.

Siendo así, podría iniciar explanando.... ¿Qué significa educar? Si el educar, "[...] es la omnipotencia de las determinaciones biológicas ambientales como constructoras de la personalidad actual y futura del hombre, y correlativamente, permitir que este acrecente su propia marca en la construcción de su destino" (HABERMAS, 2002a, p. 190), y si el filosofar es el acto reflexivo que se vuelve sobre la praxis humana; entonces puedo concluir que la educación pensada sobre la óptica filosófica consiste en la reflexión sobre los problemas que la realidad educacional presenta, deparándose la filosofía no sólo con las prácticas educativas - formales e informales, sino también con la función de atribuirle un significado a esta acción en sus particularidades y finalidades propuestas. En otras palabras, es parte de la actitud filosófica preguntar: ¿Ontológicamente, cuál es el sentido de la acción educativa del enseñar y del aprender dentro de la sociedad? ¿Epistemológicamente, cómo es posible construir el conocimiento y cómo es apropiado? ¿Metodológicamente, qué métodos deben/pueden ser aplicados? ¿Éticamente, qué valores son los establecidos para ser enseñados?

Por medio de la teoría de Habermas y de la filosofía de la educación, puedo pensar en los fundamentos de la acción cotidiana de los sujetos en la escuela, posibilitándome este ejércicio una reflexión global, crítica y rigorosa sobre la educación: ¿Cuáles serían hoy sus objetivos? ¿Qué se espera de la acción educativa en su interacción con el mundo social? ¿Hasta que punto mediados por la escuela y por las prácticas pedagógicas establecidas en el proceso de enseñanza/aprendizaje tendríamos la posibilidad de transformar la sociedad y velar por la autonomía y emancipación de los actores sociales? Si se define la Filosofía Antigua como la filosofía del ser humano, y la Filosofía Moderna, la filosofía de la conciencia humana, entonces la Filosofía Contemporánea podría analizarla como la filosofía de la acción humana, donde la cuestión ética y el acto educativo ganan enorme fuerza e importancia en el escenario atual, pues es el hombre-educador quien entra en contacto cotidianamente con la práctica y con la realidad a ser transformada. $\mathrm{O}$ sea, en la conceptuación del Mundo de la Vida, Habermas (2002b), verificó un mundo común a todos estructurado por tres componentes: los modelos culturales, las formas de ordenación y las estructuras de la personalidad. Mundo correspondiente a las formas simbólicas y a las acciones simbólicas, a la socialización y a los modos de coordenar estas acciones, y al entendimiento entre los organismos humanos (HABERMAS, 1980). Personas entrecruzándose en todos los sistemas por medio del lenguaje cotidiano multifuncional, comprendiendo la interrelación entres los componentes del mundo de la vida y el ser humano, al configurar como unidad fundante la posibilidad de la acción, en cuanto acción pragmática; o sea, la práctica comunicativa cotidiana, en la cual el mundo de la vida está centrado, alimentándose "[...] de un juego conjunto, resultante de la producción cultural, de la integración social y de la socialización, y ese juego está a su vez, enraizado en esa práctica" (HABERMAS, 2002b, p.100).

Aunque Habermas (2002a) considere que el "mundo de la vida" complemente la "noción de la acción comunicativa", partiendo de las formulaciones de Husserl, que construye el concepto "[...] como crítica a la razón, oponiéndolo a las idealizaciones objetivas que transforman el campo de las ciencias naturales como un en-si de hecho; también considera el mundo de la vida como 
'[...] el saber-sobre-un-paño-de-fondo' " (HABERMAS, 1990, p. 66), que oportuniza el encuentro de las nuevas generaciones con el saber histórico y socialmente construido, al mismo tiempo que posibilita la inserción de los sujetos en la sociedad y en la cultura por medio de la educación. Dicho de outra forma, el objetivismo no impide a la ciencia penetrar en la praxis de la vida, como creía Husserl. "El proceso se da integradamente. Aunque, no se realice en un nivel de eficiencia práctica en el sentido de una creciente racionalidad de la acción" (HABERMAS, 2008, p. 311), donde los individuos que reconstruyen un repertorio de saberes, actitudes y procedimentos referentes a las estructuras simbólicas del "mundo de la vida", compuestas por un conjunto de significados e interpretaciones (mediados por el acto educativo) se les torna posible la interacción y la participación en colectivo, además de concientizar los fundamentos para la societización; o sea, es imprescindible entender que "toda tradición cultural es simultáneamente un proceso de formación para sujetos capaces de acción y fallas, los cuales se forman en el interior de ella y que, por su turno, mantienen viva la cultura" (HABERMAS, 2002b, p. 100). Por eso, opone el "mundo de la vida" a las idealizaciones que parten de presupuestos trascendentales, siendo antes una práctica natural de la vida y de la experiencia de mundo, conceptos que se derivan de datos empíricos expresados por medio del lenguaje en este proceso de socialización que se forman los sujetos capaces de actuar, de reaccionar, de hablar, renovando y estabilizando la sociedad, comprendida ésta como la totalidad de las relaciones legitímamente ordenadas; conflictos que si no se excluyen en el escenario social, pueden amenizarse (HABERMAS, 2001), por medio de una educación sustentada en la práctica de la libertad (FREIRE, 2014).

Las políticas educacionales tematizadas a partir de las diversas realidades culturales se han asentado en diferentes países, producto de la influencia de los diferentes escenarios anteriormente expuestos. Propuestas que ni antagónicas, ni semejantes, tienen objetivos y proyectos distintos que coexisten en un complejo tejido societal; o sea, "[...] el encuentro entre culturas no es producido sólo entre sociedades a nivel global, sino también entre grupos sociales que pertenecen a una misma sociedad [...] que supuestamente homogénea [se compone de] diferentes tribus" (CANDAU, 2002, p. 74). Grupos que coexisten de orígenes étnicos o geográficos diversos, de lenguas diferentes, con adhesiones religiosas y valores contrapuestos, donde la visión de totalidad se hace necesaria para establecer puntos de contactos. Acciones necesarias en sociedades heterogéneas, donde el poder adquisitivo no solamente exclue; pesa también el identitario. Individuos que identificándose, por la religión o por la etnia, por las diferencias de sexo o de orientación sexual, o por pertenecer a otra cultura, transformaron la sociedad contemporánea en multicultural y transcultural. En esta perspectiva, "si el multiculturalismo verdadero se desarrolla concretamente como interculturalismo, esto exige al mismo tiempo un fundamento transcultural" (FORQUIN, 1993, p. 141). En otras palabras, la educación intercultural se estabelece, si se considera la tensión latente entre lo universal y lo particular, al asumirse que cada cultura tiene una lógica que debe ser entendida, como el lente por medio del cual, el hombre ve y se ve en el mundo (no necesariamente implicando exclusión) ya que en el processo de "hibridación cultural", diferentes mezclas culturales se interpenetran (CANDAU, 2002). En América Latina el intercambio/mezcla entre los grupos étnicos y el sincretismo religioso dieron lugar a mundos hasta hoy claramente diferenciados, que transitan de lo culto a lo popular, de lo tradicional a lo moderno, de lo urbano a lo rural, trayendo consigo lo que entonó Canclini (1997) como "hibridación cultural", quando intenta explicar cómo "[...] dentro de la crisis de la modernidad occidental - de la cual, América Latina es parte -, son transformadas las relaciones entre tradición, modernismo cultural y modernización económica" (CANCLINI, 1997, p. 2).

Analizar las transformaciones socioeconómicas y educativas sufridas por la sociedad atual, específicamente en latinoamérica, es antes de todo discutir las relaciones que se establecen entre 
educación y trabajo, lo que imposibilita relegar a segundo plano la importancia de la intervención pedagógica en esa relación y sobre todo el papel del educador. En este escenario, su función como mediador de la producción del conocimiento, es estimular partiendo de una práctica reflexiva y comprometida, tanto la conciencia ciudadana y la autonomía de los formandos, cuanto las potencialidades, las habilidades y las competencias que garanticen la capacidad de movilizar saberes que permitan la intervención del sujeto en su medio, si fuese necesario. Por tanto, la acción pedagógica en cuanto práctica específica tiene un papel fundamental, al propiciar la articulación entre el desempeño productivo de los sujetos y sus reales necesidades sociales, equilibrándose la competencia técnica esperada como prerrequisito de inserción en el mercado de trabajo y la función social de la educación; esto es, promover por medio de estrategias pedagógicas, metodologías renovadas y práticas innovadoras la humanización de las relaciones en el trabajo, lo que puede apuntar para el aumento de la productividad, no consituyéndose este aspecto lo más esencial.

Los efectos de las reformas educativas condicionadas por otras de carácter socio-económico, colocan en duda el papel de la escuela y de su efectividad de prepararnos para.....? La crisis educacional denuncia diagnósticos familiares y otros nuevos, afectando las políticas educativas, las instituciones escolares, la formación de los profesores (en ejercicio o no), los currículos, la estructuración de los sistemas de gestión, la complicidad de las escuelas con las familias, los métodos educativos y las metodologías aplicadas. Este cuadro coloca los docentes a solucionar problemas creados por las transformaciones tecnológicas y los nuevos espacios que sorprenden por la desertificada austeridad, caracterizándose la modernidad "[...] por la insatisfacción que nos mueve a perfeccionar lo existente, a crear, a percibir, a distribuir y a satisfacer necesidades" (SACRISTÁN, 2002, p. 39). Tal vez una de las más importantes competencias "[...] para los investigadores, profesores y legisladores educacionales sea la de estar siendo orientados para el futuro y ser sensibles a los cambios en la sociedad" (CENÁRIOS, 2001, p. 3).

Sousa (2002, p. 703), al referirse al Scenario Planning nos afirma que:

[...] un buen escenario no es aquel que retrata el futuro rigorosamente, más el que proporciona la oportunidad de levantar cuestiones pertinentes y de exponer la mente a ideas y perspectivas a partidas impensables, de forma a explorar aspectos emergentes. [...] el Scenário Planning parte del principio de que una buena decisión o estrategia es aquella que atraviesa diversos futuros posibles, face a la imposibilidad de saber exactamente como el futuro se desarrollará. [...] no se puede diseñar apenas un escenario, sino un conjunto de escenarios. Esto es, dos o más historias construidas sobre el futuro, cada cual delineando un mundo distinto y plausible en que podamos vivir y trabajar un dia. (subrayado por la autora).

La educación en el escenario actual no es más pasible de reduccionismos o interpretaciones simplistas. Ella es amplia, compleja, contradictoria, polisémica y polémica, lo que me direcciona a intentar entender, cuáles son las necesidades generadas, las competencias requeridas y los desafíos propuestos, destacándo aquí las tendencias que posibilitarán una educación más igualitaria (o como mínimo) más justa, transformando las escuelas actuales en comunidades de aprendizaje preocupadas con el diálogo y con lo dialógico, que promuevan las habilidades de selección y el procesamiento de la información, la autonomía y la capacidad para tomar decisiones, así como el trabajo en grupo, la polivalencia y la flexibilidade, parecendo que en esta flexibilidad se resume a la nueva manera de entender el nuevo contrato social.

Concebir diferentes escenarios para el futuro estimula la sensibilidad de los educadores para las tendencias y el desarrollo del "por venir", que según Derrida (1994, p. 12) "esta pregunta llega 
(caso llegue) e interroga sobre lo que vendrá en el por venir. Vuelta para el por venir, caminando en su dirección, [viniendo] tambien de ahí, [proviene] del por venir". Estrategia de doble dirección que puede estimular la imaginación de las personas actuantes en la educación y debe orientar sobre la toma de decisiones, despertando la tendencia para la proactividad y la transformación, para la construcción de nuevos escenarios y la visión futurologista nas formas de ser y fazer no ato de educar. En otras palabras, como diría Bourdieu (2011), tenemos derecho a un "utopismo racional" en los límites de lo posible, siendo indispensable "[...] como instrumento de tranformación del mundo social [...] definir los límites de lo que se puede hacer, e ir tan lejos cuanto sea posible, o pasar de esos límites, con un reducido chance de tener éxito (BOURDIEU; CHARTIER, 2011, p. 42).

Estos escenarios se encuentran bifurcados entre individualismo/coherencia social (en la horizontal) y pragmatismo/idealismo (en la vertical), cuando se refieren a lo social y a lo educacional, traduciéndose los mismos en dos puntos de intersección y divergencias: la globalización/fragmentación y la competitividad/solidaridad, reflejándose ambos en las disposiciones que giran en torno de las tecnologías de la información. Dicho de otra forma, "lo que define el desarrollo de la educación no son ni las necesidades del mañana, ni los cambios en la sociedad, y sí, los problemas organizacionales en nuestras escuelas" (CENÁRIOS, 2001, p. 3), que transitan entre polaridades escenográficas que se posicionan en una eterna lucha de contrarios. La escuela debe asomarse a la vida, a la sociedad, a lo que la rodea, no para substituir, con los materiales que el medio proporciona, su propia misión (SACRISTÁN, 2013), sino para proyectarse sobre todos esos materiales/ instrumentos, evitando perder su función iluminista - como se enlaza el pasado con el presente, el desvelamiento de los avances, de los problemas y hasta de los retrocesos, trascendiendo el reino de lo aparente -, aunque para eso precise contar con otras tecnologías; o sea, "la imprenta no anuló la educación formal, mas proporcionó una herramienta básica: no le quitó el sentido, se lo dió. Esas nuevas tecnologías son posibilidades que suman, en vez de substraer" (SACRISTÁN, 2013, p. 53).

En la postmodernidad, como condición de los tiempos que estamos viviendo, no hay lugar para utopías estrechas que profeticen un tipo humano nuevo y una sociedad ideal. En esa dirección, una visión menos normativa de la escuela, es comprenderla "como un espacio de vivencia de todo tipo de aprendizaje que los(as) alumnos(as) obtienen como consecuencia de estar siendo escolarizados(as) y socializados(as) [...]" (ARROYO, 2005, p. 43). La sociedad actual debe caracterizarse por pensar-sobre-si constantemente y decidir entre las opciones posibles, ya que las tendencias para el futuro son en su mayoría no lineales; es decir, "[...] mirar para el futuro significa estar delante de un mar de incertezas.[...] Las tendencias deben ser interpretadas, las probabilidades de cambio deben ser llevadas en consideración y las relaciones con otras tendencias son necesarias" (CENÁRIOS, 2001, p. 3).

La escuela, como estructura de una sociedad capitalista marcada por las contradicciones, recibe influencia de aquello que ocurre en su entorno. Cuando los aspectos burocráticos se sobreponen a los pedagógicos, cuando el cumplimiento de las normas y propuestas elaboradas por los órganos centrales interfieren excesivamente en la autonomía de la escuela, cuando no se legitima el discurso de los educadores, cuando no hay espacios para discusiones y trabajos colectivos, cuando los actores envueltos en el proceso no tienen una atitud participativa en su totalidad concreta, todos estos aspectos constituyentes del trabajo educativo brasileño (haciendo un breve análisis del cotidiano de las escuelas a la luz de la teoría habermasiana) me permiten identificar los aspectos relacionados a la acción instrumental, que acaban sobreponiéndose a la esfera comunicativa. Desde este punto de vista, la escuela tiene que estar vigilante con las diferentes tendencias que deben ser analizadas, consultadas y discutidas en colectivo: la razón democrática, la razón del sujeto, la razón de la incorporación en el mundo y la razón cultural de la educación formal. Los agentes envueltos no son exclusivamente los profesores, mas toda la 
comunidad, dependiendo cada vez más la educación de una realidad contextual más amplia. La transformación de la escuela en comunidad de aprendizaje debe ser la respuesta igualitaria para la transformación social, aunque tratamiento igual no signifique un tratamiento uniformizante, "[...] que no respeta, patroniza y apaga las diferencias, [es decir] igualdad que se constituya en un diálogo entre los diferentes, capaz de explorar la riqueza que viene de la pluralidad de tradiciones y de culturas" (CANDAU, 2002, p. 71). Comunidad de cooperación que se fundamente en la utilización de las habilidades comunicativas posibilitándonos la participación más reflexiva y crítica en la construcción de la sociedad, formando personas peritas en aprender y en cambiar. En síntesis, la cuestión no es tanto "[...] proporcionar el pescado, como permitir la adquisición de estrategias flexibles de pescar" (SOUSA; FINO, 2001, p. 10), formando los alumnos y los profesores en formación, no para la vida estable; por el contrario, preparándolas para la inestabilidad, para las incertezas, para los cambios/riesgos y para las nuevas oportunidades.

Los educadores, deben promover situaciones pedagógicas de intervención que apunten para el desarrollo pleno de las potencialidades de los sujetos para que éstos sean capaces de realizar una lectura crítica y sepan posicionarse frente a las demandas sociales. Los desafíos propuestos para el trabajo docente es identificar las bases ideológicas que originan esos imperativos de formación humana, comprendiéndose la necesidad de formar sujetos polivalentes, flexibles y participativos que, atiendan a las perspectivas del mercado de trabajo y actúen en cuanto sujetos innovadores, críticos y transformadores; es decir, "[...] toda educación debe ser un encuentro de diálogo entre los hombres [y mujeres], que mediatizados por el mundo, lo 'pronuncien', o sea, lo transformen, y, transformándolo lo humanicen para la humanización de todos" (FREIRE, 2014, p. $65)$.

\section{3 | CONCLUSIÓN}

Con la intención de concluir, pienso que la educación tiene el papel político, social y ético de contribuir para contestar y fundamentar estas dos dimensiones aparentemente contradictorias, "[...] ser un instrumento para la conquista de la autonomía y de la libertad [y] fomentar el establecimiento de lazos sociales para la aproximación con los demás y para la convivencia pacífica con ellos" (SACRISTÁN, 2002, p. 103). En ese sentido, la misma puede concretizarse a partir de varios aspectos:

a) del aprendizaje dialógico, el cual se basa en el diálogo igualitario fundamentado en la validez de los argumentos y no en criterios impuestos por un saber culturalmente hegemónico;

b) de la inteligencia cultural que no se reduce a la dimensión cognoscitiva basada en la acción lógica, observando también la pluralidad de dimensiones de la interacción humana;

c) de la ruptura con el discurso de la modernidad tradicional sustentado en teorías conservadoras que niegan las posibilidades de cambio y de transformación;

d) de la dimensión instrumental, no contraponiéndose al diálogo, sino incluyéndolo y siendo criticado por la colonización tecnológica del aprendizaje;

e) de la creación del sentido para cada un por medio de la potencialización de la apropiación, que posibilite las interacciones establecidas entre los individuos;

f) de la solidaridad como expresión de la democratización de los diferentes contextos luchando por eliminar la exclusión y, por último, de la igualdad de las diferencias.

Pero Habermas (2002b) no erra al mostrar que, por más que el sistema invada la escuela se percibe la sobrevivencia de los espacios comunicativos, que los profesores aunque sean obligados a seguir normas y programas preestablecidos ellos continuan teniendo alguna autonomía en sus clases, que el ambiente escolar aunque esté controlado por órganos ajenos a su realidad, aún 
así, la escuela tiene la oportunidad de construir su propia identidad en conjunto con los actores que la conforman. Para este autor, la educación es el "mundo de la vida" y el espacio de "la acción comunicativa", y la escuela, el local privilegiado de comunicación e interacción, del encuentro de identidades singulares y diferentes, del diálogo y de los intercambios, el espacio por excelencia de la comunicación; del alter y del ego, espacio donde objetivamente se tejen las subjetividades socializadas de los sujetos.

En la opinión de Santos (2004), el único modo eficaz y emancipatorio para Brasil enfrentar la globalización neoliberal es contraponerle una globalización alternativa y contrahegemónica, que viene caminando a pasos lentos (con adelantos y retrocesos) en los últimos diez años. Un proyecto nacional centrado en opciones políticas dialogantes democráticamente que cualifiquen la inserción del país en contextos de producción y de distribución de conocimientos cada vez más transnacionales, siguiendo de cerca el presupuesto tácito de la orden política (BOURDIEU; CHARTIER, 2011). La nueva transnacionalización alternativa y solidaria tiene que fundamentarse en las nuevas tecnologías de la información/comunicación "[...] y en la constitución de redes nacionales y globales donde [circulen] nuevas pedagogías, nuevos procesos de construcción del conocimiento científico y otros nuevos compromisos sociales, locales, nacionales y globales" (SANTOS, 2004, p. 56), reconociéndose en esta inclusión, los derechos fundamentales del hombre. ¡Sea brasileño o no! Siendo así, considero la validez global de la inclusión humana, en una democracia cosmopolita y mundial, donde el diálogo y la dialogación entre iguales o entre diferentes se mantenga por todos y por el bien de todos! En otras palabras, utilizando el argot popular, me autorizo a proponer una reflexión sobre este proverbio chino de un autor desconocido: "Si se desea un año de prosperidad, cultivemos granos. Si se quiere diez años, cultivemos árboles. Pero, para 100(cien) años, es necesario e imprescindible que cultivemos gente", y este ciertamente, es el sentido de la planificación de nuevos escenarios educacionales y de la educación! 


\section{Referências}

ARROYO, M. Educação de jovens e adultos: um campo de direitos e responsabilidade pública. In: SOARES, L.; GIOVANETTI, M. A.; GOMES, N. L. (Org.). Diálogos na educação de jovens e adultos. Belo Horizonte: Autêntica, 2005, p. 19-50.

BOURDIEU, P.; CHARTIER, R. O sociólogo e o historiador. Belo Horizonte: Autêntica Editora, 2011.

CASTELLANOS, S. L. V. Da crise paradigmática da ciência à crise paradigmática na educação. In: CASTELLANOS, S. L. V. (Org.). Conhecimento científico: entre saberes e fazeres pedagógicos. São Luís: EDUFMA, 2013.

CANCLINI, N. G. Culturas híbridas: estratégias para entrar e sair da modernidade. São Paulo: EDUSP, 1997.

CANDAU, V. M. Sociedade, Educação e Cultura(s): questões e propostas. Petrópolis: Vozes, 2002.

CENÁRIOS para o futuro da educação do professor na Europa. Amsterdã: Centro 19 de Pesquisa e desenvolvimento, 2001. Mimeografado.

CHARTIER. R. Prefácio. In: BOURDIEU, P.; CHARTIER, R. O sociólogo e o historiador. Belo Horizonte: Autêntica Editora, 2011. p. 07-14.

DERRIDA, J. Espectros de Marx: o estado da dívida, o trabalho do luto e a nova internacional. Rio de Janeiro: Relume Dumará, 1994.

FREIRE, P. Pedagogia do oprimido. 57. ed. Rio de Janeiro: Paz e Terra, 2014.

FORQUIN, Jean-Claude. Escola e cultura: as bases sociais e epistemológicas do conhecimento escolar. Porto Alegre: Artes Médicas, 1993.

HABERMAS, J. Cuestiones y contracuestiones. In: HABERMAS, J. Habermas y la modernidad. 2. ed. Madrid: Tecnos, 2008. p. 305-343.

Pensamento pós-metafísico. Rio de Janeiro: Tempo Brasileiro, 2002a.

Agir comunicativo e razão descentralizada.

Rio de Janeiro: Tempo Brasileiro, 2002b.

Técnica e ciência como ideologia. Lisboa: E-dições 70, 2001.

O discurso filosófico da modernidade. Lisboa: Dom Quixote, 1990. p. 89-108.

Técnica e ciência enquanto "ideologia". In: Os Pensadores. São Paulo: Abril Cultural, 1980. p. 313-343.
JAY, M. Habermas y el modernismo. In: HABERMAS, J. Habermas y la modernidad. 2. ed. Madrid: Tecnos, 2008. p. $195-220$.

McCARTHY, T. Reflexiones sobre la racionalización en la teoría de la acción comunicativa. In: HABERMAS, J. Habermas y la modernidad. 2. ed. Madrid: Tecnos, 2008. p. 277-304.

McLAREN, P. Multiculturalismo revolucionário: pedagogia do dissenso para o novo milênio. Petrópolis: Vozes, 2001. p. $237-289$.

Pedagogia revolucionaria em tempos

pós-revolucionario: repensar a economia política da educação critica. In: IBERNÓN, F. (Org.). A educação no século XXI: os desafios do futuro imediato. 2. ed. Porto Alegre: Artes Médicas Sul, 2000. p. 121-139.

RIGAL, L. A escola crítico democrática: uma matéria pendente no limiar do século XXI. In: IBERNÓN, F. (Org.). A educação no século XXI: os desafios do futuro imediato. 2. ed. Porto Alegre: Artes Medicas Sul, 2000. p. 171-194.

RORTY, R. Habermas y Lyotard sobre la pósmodernidad. In: HABERMAS, J. Habermas y la modernidad. 2. ed. Madrid: Tecnos, 2008. p. 221-242.

SACRISTÁN, J. G. A educação que temos, a educação que queremos. In: IBERNÓN, F. (Org.). A educação no século XXI: os desafios do futuro. 2. ed. Porto Alegre: Artes Médicas I, 2000. p. 37-61.

Educar e conviver na cultura global: as exigências da cidadania. Porto Alegre: Artmed, 2002. p. 99-144.

SANTOS, B. de S. A universidade no século XXI: para uma reforma democrática e emancipatória da universidade. São Paulo: Cortez, 2004.

SOUSA, J. M. Trabalhar com cenários do futuro. In: FERNANDES, M. et al. (Org.). O particular e o global no virar do milênio: cruzar saberes em educação. Lisboa: Edições Colobri; Sociedade Portuguesa de Ciências da Educação, 2002. p. 699-706.

SOUSA, J. M.; FINO, C. N. As TIC abrindo caminho a um novo paradigma educacional. In: SILVA, B. D. da; ALMEIDA, L. S. (Org.). Actas do VI Congresso Galaico-Português de Psicopedagogia. Braga: Centro de Estudos em Educação e Psicologia, 2001. p. 371-381. v. 1.

TOURAINE, A. Um novo paradigma. 2. ed. Portugal: Instituto Piaget, 2013. 